\title{
The Contribution of COVID-19-Forced Transformations in Critical Care Delivery to Patient Mortality: Still an Underexplored Association
}

\author{
Lavi Oud
}

\section{To the Editor}

Reports on the outcomes of critically ill patients with coronavirus disease 2019 (COVID-19) during the early phase of the pandemic described very high short-term mortality rates [1-4], compared to patients with other viral pneumonias [5], with decreasing mortality over the next few months [5-8]. The latter trends were generally ascribed to improving clinical experience and standardization of care in individual hospitals and health care systems [7-9].

\section{Pandemic-Induced Transformations in Critical Care Delivery}

An earlier perspective piece by Morens and Fauci, reflecting on the 1918 influenza pandemic, noted presciently that the most difficult challenges in the event of future similar public health crisis would be "to increase medical capacity and resource availability (e.g., hospital beds, medical personnel...)...Health care systems could be rapidly overwhelmed by the sheer number of cases" [10]. However, the prognostic implications of the profound transformations in the structure and process of critically care delivery due to COVID-19-related healthcare system strains were generally not directly examined, even when noted $[3,6,8,9]$, in the growing volume of reports on the epidemiology and outcomes of critical illness associated with COVID-19, constraining our understanding of how best to approach the ongoing and future pandemic-level health crises. As clinicians, healthcare systems and policy makers continue to grapple with numerous challenges during the ongoing pandemic, the COVID19-related transformations in three structure and process areas in the delivery of critical care highlighted below represent some of the key challenges faced by countries and regions irrespective of being considered high- or low-resource in the pre-pandemic era.

Manuscript submitted May 27, 2021, accepted June 8, 2021

Published online June 25, 2021

Division of Pulmonary and Critical Care Medicine, Department of Internal Medicine, Texas Tech University Health Sciences Center at the Permian Basin, Odessa, TX 79763, USA. Email: lavi.oud@ttuhsc.edu

doi: https://doi.org/10.14740/jocmr4531
The rapidly evolving shortages of intensive care unit (ICU) beds brought by the surge of COVID-19 patients have led to increasing use of alternative spaces for care of the critically ill, including repurposing for ICU care step-down units, medical/ surgical wards, clinical spaces not typically dedicated to inpatient care, and creating ICUs in areas not typically dedicated to health care [11]. The prognostic implications of increased use of critical care spaces beyond those of existing ICUs have been examined in a recent multicenter study by Toth and colleagues on the impact of increased surge in New York City. The investigators found that the odds of in-hospital mortality of COVID-19 patients were $40 \%$ higher at high surge levels (defined as use of operating rooms, general wards, and parking spaces), following adjustment for numerous patient-level factors [12]. Importantly, even an admission to an ICU of a different specialty than an "ideal" one (e.g., surgical ICU instead of a medical ICU), termed "boarding" [13], which was used as reference in the study by Toth et al [12], has been found to be associated with increased adjusted risk of death in the general population [13]. It was hypothesized that discoordination and delays of care, and disruption of established team operations related to disrupted geographic co-location contributed to the adverse outcomes of boarding [13]. Several recent studies have included measures of pandemic-related demand for critical care services in their modeling of patient outcomes. However, these were mostly composite proxy measures, such as the number of the pre-pandemic ICU beds [1] or COVID-19 patient occupancy of pre-pandemic ICU beds [14], which do not examine separately the prognostic impact of actual use of alternative care spaces and the local approaches to critical care staff shortages (see below), thus providing actionable insights into neither.

In addition, the corresponding shortage in critical care-trained clinicians was addressed by hospitals through multiple strategies, including among others increased patient/clinician ratios, asking clinicians to work longer hours or extra shifts, and using non-ICU clinicians to "extend" ICU teams [11]. Some of these approaches were previously shown to increase patient mortality [15] and it may be postulated that the other ones may have adversely affected patient outcomes. However, the prognostic implications of the individual strategies used to address COVID-19-related staffing shortages or their combinations remain unknown.

Last, the patient isolation measures mandated by the COVID-19 pandemic were unprecedented in scale and challenges in availability of required personal protective equipment and effects on care processes even in otherwise high- 
resource health systems. Lesser measures of patient isolation were shown to reduce, as expected, time of clinicians' interactions with patients and were associated with increased risk of adverse outcomes [16]. It is plausible that COVID-19-related isolation measures had adverse impact on outcomes of the critically ill. Presently, the impact on patients' outcomes of the large scale isolation practices required for care of critically ill COVID-19 patients has not been determined.

\section{Research, Policy, and Practice Implications}

It may be hypothesized that decreasing critical care space demands and staffing shortages due to receding COVID-19 case surge during the resolution phase of its first wave coincided with gains in clinical experience and therapeutic options, thus contributing together to the reported reductions in short-term mortality of affected patients. Thus, exploring the role played by changes in each of the aforementioned structure and process areas in the outcomes of critically ill patients with COVID-19 and quantifying their impact during surge periods would be of much interest to epidemiologists and investigators involved in health services research. The optimal approaches to model these structure and process transformations remain to be explored.

However, beyond the scientific interest in the findings of such explorations, a better understanding of the contribution of each of the abovementioned changes in structure and process, overall and over time, to patients' outcomes is essential for both creation of benchmarks and to inform future efforts to identify scalable models for effective responses to the current pandemic and future public health crises.

\section{Acknowledgments}

None to declare.

\section{Financial Disclosure}

None to declare.

\section{Conflict of Interest}

None to declare.

\section{Informed Consent}

Not applicable.

\section{Author Contributions}

Lavi Oud has performed the design of work, acquisition of data, analysis and interpretation, composition, drafting, revising, editing, and final approval.

\section{Data Availability}

The author declares that data supporting the findings of this study are available within the article.

\section{Abbreviations}

COVID-19: coronavirus disease 2019

\section{References}

1. Gupta S, Hayek SS, Wang W, Chan L, Mathews KS, Melamed ML, Brenner SK, et al. Factors associated with death in critically ill patients with coronavirus disease 2019 in the US. JAMA Intern Med. 2020;180(11):14361447.

2. Arentz M, Yim E, Klaff L, Lokhandwala S, Riedo FX, Chong M, Lee M. Characteristics and outcomes of 21 critically ill patients with COVID-19 in Washington State. JAMA. 2020;323(16):1612-1614.

3. Grasselli G, Greco M, Zanella A, Albano G, Antonelli M, Bellani G, Bonanomi E, et al. Risk factors associated with mortality among patients with COVID-19 in intensive care units in lombardy, Italy. JAMA Intern Med. 2020;180(10):1345-1355.

4. Lim ZJ, Subramaniam A, Ponnapa Reddy M, Blecher G, Kadam U, Afroz A, Billah B, et al. Case fatality rates for patients with COVID-19 requiring invasive mechanical ventilation. a meta-analysis. Am J Respir Crit Care Med. 2021;203(1):54-66.

5. Armstrong RA, Kane AD, Cook TM. Outcomes from intensive care in patients with COVID-19: a systematic review and meta-analysis of observational studies. Anaesthesia. 2020;75(10):1340-1349.

6. Dennis JM, McGovern AP, Vollmer SJ, Mateen BA. Improving survival of critical care patients with coronavirus disease 2019 in England: a national cohort study, March to June 2020. Crit Care Med. 2021;49(2):209-214.

7. Zhang P, Duggal A, Sacha GL, Keller J, Griffiths L, Khouli H. System-wide strategies were associated with improved outcome in critically ill patients with coronavirus disease 2019: experience from a large health-care network. Chest. 2021;159(3):1072-1075.

8. Garcia-Vidal C, Cozar-Llisto A, Meira F, Duenas G, Puerta-Alcalde P, Cilloniz C, Garcia-Pouton N, et al. Trends in mortality of hospitalised COVID-19 patients: A single centre observational cohort study from Spain. Lancet Reg Health Eur. 2021;3:100041.

9. Roomi S, Shah SO, Ullah W, Abedin SU, Butler K, Schiers K, Kohl B, et al. Declining intensive care unit mortality of COVID-19: a multi-center study. J Clin Med Res. 2021;13(3):184-190.

10. Morens DM, Fauci AS. The 1918 influenza pandemic: insights for the 21 st century. J Infect Dis. 2007;195(7):10181028.

11. Kerlin MP, Costa DK, Davis BS, Admon AJ, Vranas KC, 
Kahn JM. Actions taken by US hospitals to prepare for increased demand for intensive care during the first wave of COVID-19: a national survey. Chest. 2021.

12. Toth AT, Tatem KS, Hosseinipour N, Wong T, NewtonDame R, Cohen GM, George A, et al. Surge and mortality in ICUs in New York City's public healthcare system. Crit Care Med. 2021.

13. Lott JP, Iwashyna TJ, Christie JD, Asch DA, Kramer AA, Kahn JM. Critical illness outcomes in specialty versus general intensive care units. Am J Respir Crit Care Med. 2009;179(8):676-683.

14. Anesi GL, Jablonski J, Harhay MO, Atkins JH, Bajaj J,
Baston C, Brennan PJ, et al. Characteristics, Outcomes, and Trends of Patients With COVID-19-Related Critical Illness at a Learning Health System in the United States. Ann Intern Med. 2021;174(5):613-621.

15. Neuraz A, Guerin C, Payet C, Polazzi S, Aubrun F, Dailler F, Lehot JJ, et al. Patient mortality is associated with staff resources and workload in the ICU: a multicenter observational study. Crit Care Med. 2015;43(8):15871594.

16. Abad C, Fearday A, Safdar N. Adverse effects of isolation in hospitalised patients: a systematic review. J Hosp Infect. 2010;76(2):97-102. 